\title{
Community Managed Disaster Risk Reduction Approach in Managing Disaster in Uganda
}

\author{
Nabalegwa Muhamud Wambede ${ }^{1}$ and Acor Jessica ${ }^{2}$
}

\begin{abstract}
Community based disaster risk reduction (CMDRR) is a community based approach in managing disaster effects on the community. This study aimed at assessing the effectiveness of this approach in mitigating the effects of disasters on the community of Amuria district, Northeastern Uganda. Sample of 300 household heads were used as respondents. Methods of data collection included questionnaires, face to face interviews with key informants, focus group discussions, observation and documents review. Results from the study indicate that CMDRR approach had performed well despite some shortcomings. It had been able to prepare the community by training them in disaster management activities, developing hazard maps, disaster plans, put up effective rescue efforts, other response and recovery measures for affected communities. However, it had failed in developing capacity among the communities to stock essential services including food, early warning systems were poor in detecting and predicting disaster and building gender and age balanced capacity in the communities.
\end{abstract}

Keywords - Disasters, Community-managed, Risk Reduction, effectiveness and Mitigation.

\section{INTRODUCTION}

World over disasters have devastated Communities for over the past decades. The number of people reportedly affected by disasters globally has increased by one-third and reported deaths have been up to $84 \%$ (HPN, 2007). If such trends continue it is estimated that, by 2050, natural disasters could have a global cost of over $\$ 300$ billion a year, and was predicted to be a key element in the failure to meet the Millennium Development Goals by 2015. Global climatic change has increased the frequency and severity of these hydro-meteorological hazards (UNDP 2004). Human deaths from drought in Africa have been the highest among all regions of the world particularly because the ten most vulnerable countries are in the sub-Saharan Africa. In Uganda it is responsible for the human loss in Karamoja region and other drought prone areas in the cattle corridor.

Community management disaster risk reduction (CMDRR) approach to managing disasters and consequently reducing poverty and vulnerability has been defined by Binas (2010) as "a process of bringing people together within the same community to enable them to collectively address common disaster risks, and pursue common disaster risk reduction measures.

\footnotetext{
${ }^{1}$ Kyambogo University - Uganda

${ }^{2}$ Amuria District - Uganda

nabalegwaa@gmail.com.
}

Despite the efforts made, Uganda has experienced a wide range of disasters directly affecting most parts in the country. The mere fact that the largest percentage of the population is poor increases their vulnerability to disasters. The only option out of this situation is for the country to mainstream DRR into programs design, project concept notes, and monitoring and evaluation in such away as gender and HIV have been included, and used as reference points, in designing and choosing programs (Concern 2005). In this case DRR and livelihoods model should be used.

CMDRR approach has been one of the proposed and tested strategies to improve on the mechanisms against disasters (Allen, 2006). In the event of drought, it is said to support innovative initiatives to bring water nearby villages and reduce the burden on women and girls. In health, it's all about the Community managing the impact of HIV/AIDS or Malaria and reducing the suffering of women and children (IIRR, 2012). A number of development partners have in the past five years used CMDRR principles to build resilience in Communities in various parts of the world, where natural and manmade disasters have devastated Communities for example pastoral communities in Kenya harvest water during the rainy period to support 10,000 heads of cattle for two months in the dry period (Korugyendo, 2012). In Uganda CMDRR is practiced by Trans Cultural Psychosocial Organization (TPO) working with the community of Kipinyang village to address their dependency syndrome as a result of displacement from Katakwi.

Amuria district is one of the Districts which have faced the effects of Kony wars and the Karamojong cattle raids. People were displaced from their homes and forced to stay in congested camps. In spite of what appears to be a clear relationship between CMDRR and disaster, very little comprehensive analysis has been undertaken to examine the real effectiveness of CMDRR, as well as the strategies, conditions, and effects that work against it. This study therefore, provided a preliminary analysis of some of the more salient aspects of the performance of CMDRR strategies or how effectively CMDRR approach has achieved its objectives in building the people in the community of Uganda and Amuria District in particular.

\section{METHODOLOGY}

The study employed survey design because this provides information about the area as it was at that time during the study. Household heads, local council leaders, technical staff and CMDRR committee members constituted the study population. Owing to the difficulties in accessing all the sub counties in the 
District, the researcher chose one out of the sixteen sub counties in the District by convenience sampling. This helped reduce the costs and save time. Through purposive sampling a majority of the local government staff (12) and councilors (17) were chosen including all the CMDRR committees who are (19) in number and the rest (252) were from the community.

\section{Data collection methods and instruments}

To reveal trends in environmental changes, livelihood strategies to disasters and performance of CMDRR committees, the field tools that were used in study included:

Semi-structured interviews with both groups and individuals to obtain both general and specific information on hazards, disaster and their effects, and the performance of CMDRR committees in the area and community perceptions on underlying causes and hazard actions.

Transect walks with key informants to view the interaction between the physical environment and human activities, focusing on land use and tenure, environmental changes and the physical area vulnerability to the disaster impact, Community mapping of topography, houses and infrastructure, and Historical profiling to identify trends in disasters and vulnerability characteristics was done. Methods used included group discussion, life histories and historical tracing to reveal trends in environmental changes, livelihood strategies and performance of CMDRR committee. Interviews with community leaders and questionnaires distributed to respondent. Also social and gender analysis and hazard impact ranking were used.

\section{Effectiveness CMDRR and preparedness of the people in Amuria district}

In assessing the effectiveness of the community managed Disaster risk reduction in the study area, the parameters that were used included; existence of emergency drills, hazard maps and capacity building activities.

\section{CMDRR and hazard maps}

The researcher intended to find out whether the community was prepared with hazard maps. The community members in the parishes were asked whether they were always prepared with hazard maps. Hazard maps are some of the requirements needed to be available to indicate that a particular community is prepared to handle disasters like floods. .

However, 194 (67.4) indicated that the communities in Amuria district were to some extent prepared with hazard maps. But an interview with some community leaders indicated that they do not have hazard maps but they do know mentally where each disaster occurs, their routes and severity. The technical officer confirmed that they do have hazard maps. One copy of the map was provided to the research to confirm. This therefore implies that although the hazard maps exist, these have not been disseminated to the community members for use. In effect it reinforced the notion that the communities should have the knowledge of the disasters likely to occur in their vicinity. Jeannette Sutton et al (2006) however emphasize the need to have hazard maps generated through knowledge sharing and or dissemination.

\section{Capacity building and CMDRR}

Capacity of the communities to respond to disasters is vital if they have to be resilient, and thereafter manage to plan for the recovery after a disaster. The capacity of the communities to respond to disaster is easily gauged by the level at which the leaders communicated the information, adaptation of the message and functionality of the CMDRR committees. From the field data, it was noted that more people acknowledged being informed about the impending disasters. There was evidence to suggest that the capacity building was done among community members in the parishes as indicated by $71.5 \%$ of the respondents. The field data indicates that the capacity of both the leaders and CMDRR committees were built. But this training was not gender and age sensitive. One key informant had this to say; 'I have been taught to see that during the farming season, I should have a separate garden of food for sale and for home use'.

\section{CMDRR and disaster preparedness plans}

Disaster preparedness plans are a prerequisite to the management of disaster because it indicates what action and resources would be required before hand in response to a disaster should it occur. The plan attempts to limit the impact of the disaster by structuring the response and effecting quick and orderly reaction to the disaster, one thing to note however is this plan should be translated into action. In this study the respondents were asked whether they had disaster preparedness plans that guide the community.

The results reveal that in the two parishes of Abarilela Sub County 203 (70.7\%) indicated that the areas had disaster preparedness plans, implying that the communities had all what it takes to manage the effects of disaster. However the interview with some key informants indicated that there is no disaster preparedness plan but they plan as disasters arise since there are no adequate resources at the sub-county, the argument of another informant who hails from Ocal parish was "unless Soroti Catholic Diocese for Integrated Development Organization (SOCADIDO) officials have it but I have never come across it, meaning the CMDRR committee doesn't have it. This was evidenced during the collapse of Adiidin dam, the committee had to call for help from SOCADIDO and could not do anything on their own".

\section{Existence of CMDRR Committees}

The existence of a trained CMDRR committee to guide the community in the pre-disaster event and after the disaster event cannot be underestimated due the roles played by the committee such as create awareness to the community in the areas such as tree planting, hygiene and sanitation, savings, upcoming disasters, use of resistant materials in construction among others. The study found out that the committees exist in the two parishes. It was established that $222(77.4 \%)$ of the respondents indicated that the CMDRR committees are in place. During the focus group discussion the respondents confirmed that they had CMDRR committees comprising of nine members and played roles like sensitizing the entire community on how to address the effects of disaster in case of its occurrence including food security, forming groups that practically fought disaster effects for example; digging the water channels, liaising with some 
NGO like SOCADIDO to provide support like construction of a dams. Adiidin dam was cited by the respondents as one which was constructed to provide water for cows to drink. In addition the respondents pointed out that the CMDRR committee also practically participated in road clearing to create path ways to access services.

\section{CMDRR and Response disasters}

This was intended to analyze the effectiveness of CMDRR in responding to disaster effectively in Abarilela sub-county. The indicators that were considered in this analysis of assessing the effectiveness of the response actions included death, loss of property and the general disruption to normal life for a long period. $186(65 \%)$ indicated that there were loss of life. However death alone is not a measure of disaster but as long as there exist a disruption in the normal functioning of a community beyond the ability of the community to cope thus requiring external support, a disaster is deemed to have occurred.

But interviews with the civil servants indicated that no deaths were recorded while politicians and the CMDRR committee members reported that some deaths occurred. This implies that if some people lost life then the CMDRR mechanisms in these parishes were not effective. Also, it seems that civil servants who are always committed in their offices have no time to get reports of the occurrences of death as a result of disasters. In an interview with respondent, he observed that no deaths had occurred in the sub county with regard to floods, on the other hand an interview with four political leaders indicated that "other people's houses collapsed on them especially in Katakwi district and Acowa sub county but not in Abarilela sub county, for us we fled to safe places" its therefore clear that the death could have been caused by other disasters such as Kony wars and the Karimojong cattle rustlers other than floods". However as stated earlier death alone is not the measure of disaster occurrence therefore in all instances the community was unable to cope on its own thus implying disaster had occurred thus the response mechanism was either slow or poor.

\section{Conclusion}

The community was to some extent prepared to respond to these disasters and the recovery process was through their own participation in constructing their own houses, which were damaged by floods, and this is the idea behind CMDRR where communities bounce back from hazards and disasters. Some tents were supplied which were not enough for the whole population. Some people were helped especially old women and men. The interview results from all the respondents indicated that the roads which got damaged by the floods have remained in a bad state up to now since 2007. Some help to respond and recover came from government and SOCADIDO. The community members themselves rebuilt their own houses. This was a good indicator of resilience in community. On the other hand the road network remained in a very poor state. The quality of education and medical services in the same way have remained in a sorry state as pupils academic performance are always poor. SOCADIDO, an NGO had spear headed the CMDRR strategy in the sub county from 2010 to 2012, this was due to level of vulnerability of the area of study to disasters. The community was sensitized as an entry point, hazard maps drawn by the community, hazards ranked and finally CMDRR committees put in place for the two parishes. As a strategy of mainstreaming, SOCADIDO distributed Akena and Migera cassava cuttings, mango and orange seedlings, onion and tomatoes improved seeds to the community. It was also found out that SOCADIDO helped to further improve people's livelihoods by sensitizing the community to establish village savings schemes and on hygiene and sanitation.

\section{REFERENCES}

[1] Allen, K. M. 2006. Community-based disaster preparedness and climate adaptation: local capacity-building in the Philippines. Disasters, 30: 80-101. https://doi.org/10.1111/j.1467-9523.2006.00308.x

[2] Binas, R. 2010. Understanding Community Managed Disaster Risk Reduction, Community Based Approach in UNHCR Operations (2008) Geneva, Switzerland.

[3] Concern (2005), Approaches to Disaster Risk Reduction, Emergency Unit 1

[4] Cord-Aid, 2010. Community Managed Disaster Risk Reduction: Experiences with Eruption of mount Merapi in Indonesia.

[5] Cord-Aid and IIRR, 2011.Community managed disaster risk reduction experiences from the horn of Africa. Disaster Risk Assessment Report

[6] Jeannette S and Kathleen T, (2006). Disaster Preparedness: Concepts, Guidance, and Research: The Natural Hazards Center, Institute of Behavioral Science, University of Colorado, Boulder, CO.http://www.colorado.edu/hazards.

[7] United Nations Development Programme, New York, and the Disaster Relief Coordinator, Geneva. United Nations Environment Programme (2008). Indigenous Knowledge in Disaster Urban Council, Sri Lanka.

[8] Korugyendo P.L and Akureje N.O. (2012), Community Managed Disaster Risk Reduction. Intervention approach and Methodlogy Empoyed in Karamoja Regional. Evaluation Report. DanchurchAid 